\title{
Carcinoma of the oesophagus: aspects of epidemiology and aetiology
}

\author{
By W. Silber, Department of Surgery, Medical School, Observatory 7925, Cape \\ Town, South Africa
}

Carcinoma of the oesophagus has been recognized since the time of Galen, and in Africa and elsewhere it has in many ways the strangest distribution of any tumour (Cook \& Burkitt, 1971).

Since the first resection of a cervical oesophageal carcinoma by Czerney in $187 \mathrm{I}$ (Wangesteen, 1956), and the successful resection of a thoracic oesophageal carcinoma by Torek in 1913 (Torek, 1913), many other therapeutic modalities have been introduced. In spite of all these advances the prognosis remains dismal-truly a disease of doom. This unfortunately is due to the invariably late presentation of all patients. Hence pessimism prevails and in many schools, palliative regimens are the order of the day rather than any consideration of cure. Thus, in the 1980 , it still remains one of the most melancholic chapters in medicine (Miller, I98I). In spite of the above situation, much work is being performed in the fields of primary and secondary prevention (Deeley, 1983).

It is mandatory for epidemiologists to learn from clinicians and to focus their attention not only on the risk factors, but also on the individuals on whom these risk factors are acting (Orchard, 1980 ).

\section{Epidemiology and incidence}

Cancer of the oesophagus, an aggressive disease, has a pattern of incidence which is remarkable in all its aspects. It is most thought provoking, as the incidence can vary 500-fold from one area to another, from one country to another and between ethnic groups in the same country. Peculiarities in the distribution of the disease may be due to host factors such as sex, age, race, family, predisposing diseases or to environmental factors (McConnell, 1978; Miller, 1981).

In recent years there has been a considerable improvement in the availability of reliable statistics. It is most difficult, unfortunately, to assess changes meaningfully in relation to past inaccurate epidemiological statistics based very often on hearsay evidence only. Analyses in general are poor, there is a wide range in areas of high and low incidence, there is the constant bugbear of migrant population groups and finally, inaccurate morbidity and mortality figures. Hence, it is impossible to compare international figures from the past literature (Case, 1961). The chief reasons for this variation are the differences in quality of the final diagnoses and the accuracy and completeness of death certificates (especially where no post-mortem examinations have been performed).

Improved and reliable statistics have become available in recent years. 


\section{Patterns of occurrence}

Time trends. In $186_{5}$ David Livingstone stated categorically that cancer did not occur in Africa. Carcinoma of the oesophagus was certainly uncommonly reported amongst the South African black population before 1940. It seems to have become a clinical problem only after World War II, and reached epidemic proportions in the middle 1950 s in a dramatic and inexplicable way. However, it has long been recognized by the black indigenous population of South Africa as the 'disease of the evil spirits' or 'as the sore which never heals'. It is interesting to note that amongst black men in Johannesburg in the 1930s, carcinoma of the oesophagus represented $2 \%$ of all forms of cancer (Berman, 1935) but was $10 \%$ in the 1950 s and $28 \%$ in the early 1960 s (Robertson et al. $197 \mathrm{I}$ ). A similar significant increase has been reported since $194^{\circ}$ amongst the black males of the Washington DC area (Anon. 1982).

It is still questionable whether the incidence of cancer of the oesophagus should be based on mortality figures. This applies particularly to previous reports from Africa and Asia. The apparent increased frequency in recent years is probably due to greater awareness and better diagnostic techniques, although the high incidence and death rate has been known for many generations amongst the Turkoman Tribes in the Caspian Littoral of Iran (Dowlatshahi et al. 1978).

International variations. The geographical distribution in the world varies considerably and is certainly more diverse for oesophageal carcinoma than for any other gastrointestinal cancer. This is noted particularly where the comparison is shown according to death rates (McConnell, 1978). In Africa, areas of high incidence exist in the Transkei (South Africa) (Rose, 1973; Warwick \& Harington, 1973) amongst the black population and an increasing incidence is being reported in the Cape coloured population of South Africa (Bradshaw \& Harington, 198I; W. Silber, unpublished results). Other areas in the world of high incidence include a belt from the Caspian Littoral in Iran to the northern provinces of China, known as the 'Asian oesophageal cancer belt' (Mahboubi et al. 1973; Kmet \& Mahboubi, 1972; Anon. 1975). Another area of high incidence is Alaska (Hurst, 1964). Areas of moderate incidence are found in France, especially in the provinces of Brittany and Normandy (Audiger et al. 1975; Tuyns \& Masse, 1975). This incidence is seven times that seen amongst men in Denmark (Waterhouse et al. 1982) but half that of the high incidence figures for black men in Soweto (Johannesburg, South Africa) (Isaacson et al. 1978).

In contrast, there are many areas thoughout the world where the incidence of oesophageal carcinoma is well below ro per 100000 population. In the USA, the incidence has remained stable for both white males and females ( 4.7 and I I 6 per 100000 repectively). The same state of affairs exists among the white males and females in South Africa, where it constitutes only 10\% of the total number seen.

Oesophageal cancer is no exception to the general rule that particular incidence patterns of a disease in a given population are the result of possible previous disease experience, environmental exposure and immuno-genetic predisposition modified by the condition of the specific ecological setting (Kmet, I 974 ). 


\section{Variations within countries}

In the Transkei (South Africa), the highest incidence (246 per 100000), was recorded in the Butterworth district (Burrell, 1957; Burrell, 1969; Rose, 1973).

The existence of contiguous districts of high and low incidence provided pointers to suspected tribal and local variations in exogenous health risks. This situation has, however, changed over the years, as this whole area is beginning to show a more diffuse involvement throughout the country.

The magnitude of difference between high and low incidences within the same countries is seen in Central Asia (Caspian Littoral), in Curacao and Brazil (Anon. 1978).

The incidence in the greater Bombay region, based on institutional mortality figures (which may be inaccurate and thus present limitations), was recorded as 14.4 and 11.0 per 100000 for males and females respectively (Paymaster, 1964; Paymaster et al. 1968; Odes \& Krawiec, 1979). An interesting point about this National group is that in 1980 , in the Beersheba area of Israel, $43 \%$ of all cases were Indian Jews who had emigrated from Bombay in 1960 , indicating a persistent incidence.

In China, the highest incidence occurs in the Northern Provinces, and in the U.S.A., areas involved arc Charlestown in South Carolina (Fraumeni \& Blot, 1977), and mention has already been made of Washington DC and Alaska.

\section{Host factors}

I. Sex. The vagaries of the sex ratios in this disease is most marked. In general, the incidence of oesophageal carcinoma is far higher in males than in females (Lovine et al. 1974), but for a number of countries (e.g. Denmark, Sweden, Norway and Germany) the sex incidence rate is about the same (Kayser \& Burkhardt, 1979). Similar sex ratios are found in areas of high incidence, e.g. some areas of the Transkei, Iran, China and Kampala, while in adjacent low-risk areas, the incidence in females is much lower (Cook, $197 \mathrm{I})$. This type of sex variation was noted by Oettle ( 1964$)$.

2. Age. The majority of cases, on clinical presentation, are in the 40-60 year age group. In some areas, for example in Iran, the disease may occur $5^{-1} 5$ years earlier (Crespi et al. 1979) than generally accepted, especially in the female (Postlethwait \& Sealy, 1979).

3. Race. There seems no valid reason for the special predilection of black races developing oesophageal cancer. According to Deeley (1983), the low socio-economic factors in the USA are implicated rather than race. The same factors may play a part in the high incidence amongst the black and coloured races of South Africa (W. Silber and A. Witz, unpublished results). In discussing carcinoma of the oesophagus with special reference to the increased incidence in the Cape coloured male, Harington \& Bradshaw ( 1977 ) suggested that the life-style of this group may be responsible. 
4. Genetic predisposition. There is conflicting evidence as to whether heredity is concerned in oesophageal carcinoma. Although no evidence of familial association was reported in the Danish study (Postlethwait \& Sealy, 1979), there are reports from Iran indicating a $28 \%$ familial incidence (Crespi et al. 1979), and another in which thirteen cases have been described in three generations (Pour \& Ghadiriam, 1974). A similar high incidence was described in Kazakhstan in Russia (Kaufman et al. 1965 ). In spite of these case reports, the weight of evidence is in favour of the view that heredity plays little or no part in the aetiology of this disease. There is, however, one definite genetic condition which is important, namely tylosis (hyperkeratosis, palmaris and plantaris).

This is determined by a single autosomal mutant gene. Families have been described in the UK but no cases have been recorded in other parts of the world (Clarke \& McConnell, 1954; Howel-Evans et al. 1958; Shine \& Allison, 1966).

5. Predisposing lesions. It is difficult to assess the importance of predisposing lesions in the development of oesophageal carcinoma. An obstructive lesion may allow exogenous agents to act over a longer period or may cause stagnant oesophagitis to develop, which in turn may undergo metaplasia or neoplasia.

(a) Chronic oesophagitis: Localized chronic oesophagitis has been described as the most frequent finding in carcinoma of the oesophagus in Iran (86\%) (Crespi et al. 1979). This has also been stated to be a constant finding in the Transkei (Rose, 198I). It is also claimed that it differs from reflux oesophagitis in that the distal oesophagus is spared (Rasmussen, 1976). This certainly has not been my experience in our surveillance trials. Were Crespi et al. (1979) noting this in established cancer cases? The cases Rose (r98I) described were post-mortem studies--were the changes definitely pre-mortem pathology?

(b) Achalasia: In the untreated or inadequately treated achalasia patients, stasis may occur which can produce stagnant oesophagitis with subsequent possible mitotic change. This incidence varies considerably throughout the world (up to 10\%) (Just-Viera \& Haight, 1969; Wychulis et al. 1971). In my own series of 214 cases of achalasia treated surgically and followed-up for 25 years, the incidence of subsequent carcinoma has been $2.8 \%$ (six cases) (W. Silber, unpublished results).

6. Pre-cancerous lesions. (a) Lye strictures: This may be associated with gross oesophageal wall damage leading to localized or diffuse strictures. The incidence of subsequent carcinoma is controversial. Some claim an incidence of up to $5 \%$ (Jerami et al. 1971).

(b) Leukoplakia: Unquestionably, oral and buccal leukoplakia is pre-malignant. However, leukoplakia is very uncommon in the oesophageal mucosa and when it occurs it has a benign natural history (D. Uys, personal communication).

Other rarer pre-cancerous lesions are heterotopic gastric mucosa, Barrett's columnar lined oesophagus and sideropenic dysphagia.

\section{Environmental factors}

No one factor or set of factors has been found to have either a strong enough association or a sufficiently constant association between countries to be 
considered a common cause (Day, 1955). Epidemiological data amongst the high incidence areas have been accumulating and the best currently available data implicate environmental factors, i.e. the general life-style as a main determinant. Further study along these lines may offer the key to the causes or prevention of some forms of cancer (Werther, 1980). However, it is accepted by most workers that the aetiology is multi-factorial.

I. Occupational hazards. Recently there has been a reported association of vulcanizing rubber and oesophageal carcinoma, but it is difficult to be dogmatic in that the induction period is seldom less than 15 years (Novell et al. 1983 ).

2. Exogenous factors. The only constant factors postulated for high, moderate and low incidence areas are tobacco and alcohol.

(a) Tobacco: The use of cigarettes, cigars or pipe tobacco all produce the same result. In the Transkei, pipe smoking may be of major importance as the residue in the stem of the bowl is sucked, scraped out, chewed or swallowed (van Rensburg et al.1983). The substances obtained from Transkei home-grown tobacco pyrolosate, which are ingested, namely 'injonga' and 'isixaxa', are known to have a higher mutagenicity than similar substances found in commercial tobacco. More men smoke in high-risk areas (86\% with $89 \%$ of these smoking pipes), compared with $44 \%$ in low-risk areas (with $30 \%$ pipe smokers) (Bradshaw \& Harington, I981). In an epidemiological study amongst the Cape coloured males, pipe smoking was of statistical significance (W. Silber, unpublished results). In Wynder's study in Sweden, it was found that of those developing oesophageal carcinoma, ${ }_{51} \%$ used cigarettes, $18 \%$ used pipes and $15 \%$ cigars (Wynder et al. 1957). Tobacco and excessive alcohol intake are accepted in most regions of high incidence in the Western countries as the chief contributory factors in carcinoma of the oesophagus. These factors may be independent of each other (Tuyns et al. 1978). Although there is no doubt about the association of smoking and high incidence of oesophageal carcinoma, much more information is still required. The exact type of tobacco used, the process of curing and concentration of tar may all influence the eventual outcome. There is no doubt that tobacco may affect the oesophageal epithelium.

(b) Alcohol: It has been suggested from various studies that alcohol taken in the form of spirits, beer or wine, is the important factor in the aetiology of oesophageal carcinoma. While it is an established fact that mostly consumers of alcohol are also heavy smokers, there are those who dissociate the two, while others feel that these two factors act in a synergistic way (Wynder \& Brom, 196r). Is it the alcohol itself or some other chemical in the spirits? Alcohol per se is not carcinogenic and its aetiological relation may be more complex than has been previously expressed. Is it the interaction with tobacco smoke or several other factors, e.g. relative differences in specific vitamins, which exacerbate the co-carcinogenic action of alcohol with genotoxic carcinogenic tobacco and smoke (Weisburger et al. 1982)? In South Africa, the association between alcohol consumption and oesophageal carcinoma has been investigated (van Rensburg, I981). In the early investigations, it was considered that the ingestion of an indigenous brew, 'cidiviki', was the chief 
factor responsible for the high incidence in Transkei. This idea has been disproved by the fact that cidiviki has now been replaced by a beer made from maize instead of sorghum, yet the incidence has not fallen.

In France, both alcohol and tobacco consumption are considered to be the most important aetiological factors, especially the ingestion of a home-brewed beverage (calvados) (Day, 1955). The type of alcohol, however, was just as important as the quantity.

Can this really be considered the aetiological factor when in areas like the Caspian Littoral (a high incidence area), the intake of alcohol is illegal and therefore insignificant? In Australia, where alcoholism and smoking are common, the prevalence of oesophageal cancer is rare.

\section{Diet and environment}

Diet may influence the incidence of cancer by ingestion of agents that are direct-acting carcinogens or their precursors, it may affect the formation of carcinogens, the activation or de-activation of carcinogens already initiated, the interaction of carcinogens with stem cells or it may modify hormonal activity. The role of the natural environment and life-style are high-risk factors which may be of importance in different areas.

Nitrosamine contamination has been incriminated, but definite proof in man is as yet lacking. This type of exposure in man is limited because the toxicity of nitrites limits the extent to which a nitrites dose can be increased to compensate for the shorter time during which it can be given to animals (Lizinksky, $198_{3}$ ). It is accepted that nitrosamine is a powerful carcinogen and can be produced in the soil where there is a molybdenum deficiency. Secondary amines, produced during decomposition of meat or fish, can also be converted into nitrosamines. In China, where there is a high incidence of Candida albicans infection in the oesophagus, it is thought that this augments the production of nitrosamines (Hsia et al. I98I). In the Linxian district of North China, nitrosamine is also found as a mutagen in pickled vegetables. The high concentration of this mutagen in food and tobacco is considered to be of great importance especially where certain dietary habits, combined with nutritional deficiencies (e.g. vitamins), exist (Ackerman et al. 1978).

In South Africa, maize grown on poor soil, especially with trace element deficiencies, seems to be liable to fungal infection, especially from the aspergillus species which are capable of producing another powerful carcinogen, aflatoxin. In other countries, carbohydrates are commonly contaminated with aflatoxin, and in Japan it is associated with the consumption of bracken fern, commonly associated with a high incidence of oesophageal carcinoma. However, there is an anomaly in that the incidence of aflatoxin contamination is very high in West Africa, where oesophageal carcinoma is low, while the opposite holds for East Africa, which is in an area low in aflatoxin, but high in carcinoma of the oesophagus.

Use of maize rather than millet and sorghum for the production of beer may be important in that this produces a chronic deficiency of a few micronutrients, e.g. riboflavin, nicotinic acid, zinc, niacin and magnesium. This deficiency does not 
occur where the diet consists of sorghum, millet, cassava, yams and peanuts (van Rensburg, I981; van Rensburg et al. 1983). It has been suggested that the diet should be modified in the following ways: ( 1 ) minimize the consumption of known carcinogens (naturally occurring or those added voluntarily on involuntarily), (2) identify mutagens in food and minimize content where possible, (3) consume alcohol in moderation, (4) prevent contaminated food with microtoxins, (5) use molybdenum as a chemical fertilizer, (6) alter bad dietary habits (HsienWen, 1982).

\section{Vitamins and oesophageal carcinoma}

The question of deficiencies of micronutrients in the diet in areas of high risk of carcinoma of the oesophagus has been the subject of much work and debate. Riboflavin deficiency has been considered to be associated with carcinoma of the oesophagus (Foy \& Mbaya, 1977; Siassi, 1980). The whole population in the Transkei is $20 \%$ deficient in vitamin $\mathrm{C}$ and nicotinic acid (Groenewald $e t$ al. 1981).

Another vitamin which has been incriminated for a long time is vitamin $A$. The deficiency of this vitamin has been known to be associated with hyperkeratization, metaplasia, dysplasia and the appearance of gross tumours of epithelium tissue. Such changes have been suggested as the basis of oesophageal carcinoma (Sporn \& Newton, 198I).

The past decade has seen a rapid escalation of interest in vitamin $A$ and its analogues (retinoids) based on the appreciation that vitamin $A$ controls epithelial tissue differentiation and may be connected with the inhibition of the development of epithelial cancer (chemo-prevention) (Sporn et al. 1976; Sporn \& Newton, 1979). This association was first noted in 1926 , when vitamin-A-deficient rats were found to develop stomach carcinoma (Fyzimaki, 1926). The deficiency of dietary vitamin $A$ has been associated with carcinoma of the lung, bladder, colon, skin and oesophagus (Hormozadiarai et al. 1975; Joint Iran-International Agency for Research: Cancer Study Group, 1977; van Rensburg et al. 1981). Vitamin A utilization is part of the 'intrinsic physiological control' in epithelial tissue that prevents the development of malignancy (Sporn, 1977), and low levels were found in cancer patients irrespective of the site or cell type (Kark et al. $198 \mathrm{r}$ ).

Retinoids have also been shown to be effective in cancer prevention by delaying the progress of pre-neoplastic to fully neoplastic cells (Merriman \& Bertram, 1979; Andries \& Smith, 1983). $\beta$-Carotene stimulates the activity of retinol in the peripheral tissue and independently quenches the energy of excited oxygen. This inhibits oxygenation and seems to prevent tumour growth and regrowth. It has been suggested that $\beta$-carotene, because of its low toxicity, may be useful in tumour prevention where prolonged administration of a protective agent would be required (Siegler et al. 1981; Simpson et al. 1982). The consistency of evidence suggests that a diet relatively high in $\beta$-carotene may reduce the risk of lung cancer, even among people who have smoked cigarettes for a number of years (Shehella, $198 \mathrm{r}$ ). There is an inverse relation between vitamin $A$ intake and carcinoma, similar to the inverse relation between cholesterol concentration and 
carcinoma. The relation, however, is stronger for retinoids than for cholesterol. Are these findings related or co-incidental (Kark et al. 1982) ?

In my surveillance studies in asymptomatic males from a high-risk area (Transkei), there seemed to be a correlation between dysplasia $(7.8 \%)$ and low serum $\beta$-carotene levels. In another study, however, (Kleinzee, North Western Cape), where the incidence of dysplasia was low, the $\beta$-carotene levels were normal (W. Silber, unpublished results).

The concentration of cellular retinoic acid binding proteins was determined in both normal oesophageal tissue and oesophageal carcinoma. In the latter, the levels were either undetectable or were significantly lower than in the adjacent tissue. This may be a good diagnostic biochemical marker for early detection of carcinoma (Dowlatshahi et al. 1983).

There was a dose-response reduction in risk associated with an increase in vitamin A; however, this disappeared when control was made for smoking and alcoholic ingestion. There was no similar dose-response reduction with increased ingestion of vitamin $\mathrm{C}$, which persisted when control was made for smoking and alcohol (Mettlin et al. 1981; Graham, 1983).

On the other hand, Wald et al. (1980) found that low retinol levels were associated with an increased risk of cancer independent of age, smoking habits or serum cholesterol (Wald et al. 1980). This once again complicated the state of affairs.

Deficiencies of zinc, magnesium or vitamin A may also contribute to the development of oesophageal cancer. This is certainly proven in the case of carcinoma of the lung (Sakula et al. 1980; Mellow et al. 1981, van Rensburg, I98I).

\section{Conclusion}

The aetiology of this disease is certainly multifactorial. There have been advances, but these are not always consistent.

There is no doubt that primary prevention-reduction in the causative factors-is, or should be, the 'best funded branch of medicine' (Doll, 1983). One possible measure, e.g. fortifying maize, may have far reaching effects. The administration of $\beta$-carotene may also possibly help to lower the incidence of carcinoma of the oesophagus.

Another aspect of vital importance is secondary prevention, i.e. early diagnosis. This is now possible utilizing a simple technique namely the Nabeya capsule, which yields a $1 \cdot I \%$ positive rate in asymptomatic males from a high risk area. (W. Silber, unpublished results).

Clearly, much more work in all fields is still necessary.

\section{REFERENCES}

Ackerman, L. V., Weinstein, J. B. \& Kaplan, A. S. (1978). Cancer in China [L. Mettlin and G. Murphy, editors]. New York: Alan R. Liss.

Anon. (1975). British Medical Fournal 270, 6r. 
Anon. (1978). Lancet i, 641.

Anon. (1982). Metropolitan Washington Regional Cancer Registry Progress Series, vol. I, pp. I $1-36$.

Andries, T. R. \& Smith, T. G. (1983). South African Medical Fournal 76, 549-550.

Audiger, J. C., Tuyns, A. F. \& Lambert, R. (1975). Digestion I3, 209-2 I9.

Berman, C. (1935). South African Medical Yournal 1, 12-30.

Bradshaw, E. V. \& Harington, J. S. (1981). Cancer Among Black Populations, pp. 17-33 [L. Mettlin and G. Murphy, editors]. New York: Alan R. Liss.

Burrell, R. J. W. (1957). South African Medical fournal 31, $401-409$.

Burrell, R. J. W. (1969). Fournal of the National Cancer Institute 43, 877-888.

Case, R. A. M. (196r). Tumours of the Oeosphagus, vol. IV, pp. I1-36. [N. C. Tanner and D. W. Smithers, editors]. Edinburgh: Livingston.

Clarke, C. A. \& McConnell, R. B. (1954). British Medical fournal ii, I 137-1 I 38.

Cook, P. J. (1971). British fournal of Cancer 25, 853-880.

Cook, P. J. \& Burkitt, D. P. (1971). British Medical Bulletin 27, 14-20.

Crespi, M., Grand, A. \& Amiro, F. (1979). Lancet ii, 21 7-221.

Day, N. E. (1955). Cancer Research 35, 3304-3314.

Deeley, T. J. (1983). Clinical Radiology 34, 587-608.

Doll, Sir R. (1983). Clinical Radiology 34, 609-623.

Dowlatshahi, K., Danashbod, A. \& Muborhans, S. (1978). Lancet i, 125-126.

Dowlatshahi, K., Mehto, R. G., Levin, B., Cerny, W. L., Skinner, D. B. \& Moon, R. C. ( 1983 ). Surgical Oncology Congress Proceedings, Denver (Abstract).

Foy, H. M. \& Mbaya, V. (1977). Proceedings of the Food and Nutrition Society 2, 357-394.

Fraumeni, J. F. \& Blot, W. J. (1977). Fournal of Chronic Diseases 30, 759-767.

Fyzimaki, Y. (1926). Cancer Research 10, 469-472.

Graham, S. (I983). Cancer Research 42 (Suppl.), 2409-2413.

Groenewald, G., Langenhoven, M. C., Beyers, M. J. \& du Plessis, J. P. (1981). South African Medical fournal 60, $964-967$.

Harington, J. \& Bradshaw, K. (1977). Carcinoma of the Oesophagus, pp. 43-5 I [W. Silber, editor]. Cape Town: A. A. Balkema.

Hormozadiarai, H., Day, N. E. \& Avamesh, B. (1 975). Cancer Research 35, 3493-3498.

Howel-Evans, W., McConell, R. B., Clarke, C. A. \& Sheppard, P. M. (1958). Quarterly fournal of Medicine 27, 41 3-429.

Hsia, C. C., Sun, T. T., Wang, Y. Y., Anderson, L. M., Armstrong, D. \& Good, R. A. (1981). Proceedings of the National Academy of Science, USA 78, 1878-1881.

Hsien-Wen, H. A. (I 982). Cancer Prevention in Developing Countries, pp. 429-433 [K. Aoaki, S. Tominaga, T. Hirayama and Y. Hirota, editors]. Nagoya: University of Nagoya Press.

Hurst, E. S. (1964). Cancer $17,1187$.

Isaacson, C., Selzer, G. \& Kaye, V. (1978). South African Cancer Bulletin 22, 49-89.

Jerami, S., Booth, A. \& Pate, J. W. (1971). Chest 59, 226-227.

Joint Iran-International Agency for Research: Cancer Study Group (1977). Fournal of the National Cancer Institute 59, I $127-1$ I 38.

Just-Viera, J. O. \& Haight, C. (1969). Surgery, Gynaecology and Obstetrics 128, 1081-1095.

Kark, J. D., Smith, A. H. \& Hames, C. G. (1982). British Medical Fournal 284, I 52-1 54 .

Kark, J. D., Smith, A. H. \& Switzer, B. R. (1981). Fournal of the National Cancer Institute 66, 7-16.

Kaufman, B. D., Liberman, Is. \& Tyshetskii, V. (1965). Vop Oncology I I, 78 (Translation).

Kayser, R. K. \& Burkhart, H. (1 979). Journal of Cancer Research and Oncology 93, 301-308.

Kmet, J. (1974). Proceedings of the International Cancer Congress, Florence (Abstract).

Kmet, J. \& Mahboubi, E. (1972). Science 175, 846-853.

Lizinsky, W. (1983). Cancer Research 43 (Suppl.), $244^{1-2443}$.

Lovine, D. V., Deves, S. S. \& Goodwin, J. D. (1974). Cancer Rates and Deaths OHEW Publications no. 14, p. 79. Washington, DC: Government Printing Office.

McConnell, R. B. (1978). Journal of the Royal Society of Medicine 7x, 278-281.

Mahboubi, E., Kmet, J., Cook, P. J., Day, N. E., Ghadiriam, P. \& Salmosizadeh, S. (1973). British fournal of Cancer 28, 197-2 I4.

Mellow, M. H., Layne, E. A., Lipman, T. O., Kaushik, M., Hostetler, C. \& Smith, J. C. (1981). Gastroenterology 80, 1229 (Abstract). 
Merriman, R. L. \& Bertram, J. S. (1979). Cancer Research 39, 1661-1666.

Mettlin, C., Graham, S., Priori, R., Marshall, J. \& Swanson, M. (1981). Nutrition and Cancer 2, $143-147$.

Miller, A. B. (1981). Proceedings of the National Conference on Gastrointestinal Cancer 28, $2533^{-2540 .}$

Novell, S., Ahlbom, A., Lipping, H. L. \& Osterblom, M. (1983). Lancet i, $462-463$.

Odes, H. S. \& Krawiec, P. (I 979). Frontiers of Gastrointestinal Research, vol. 4, pp. 96-100 [E. Rosin, editor]. Basel: Karger.

Oettle, A. G. (1964). Fournal of the National Cancer Institute 33, 383-436.

Orchard, T. J. (1980). Lancet ii, $845-846$.

Paymaster, J. C. (1964). Cancer 17, 1026-1034.

Paymaster, J. C., Sanghivi, L. D. \& Gantharan, P. (1968). Cancer 21, 279-288.

Postlethwait, R. W. \& Sealy, W. C. (1979). Surgery of the Oesophagus, pp. 616-648 New York: Appleton, Century-Croft.

Pour, P. \& Ghadiriam, P. (1974). Cancer 33, 1649-1652.

Rasmussen, C. W. (1976). American fournal of Gastroenterology 65, 409-415.

Robertson, M. A., Harington, J. S. \& Bradshaw, E. (1971). British Fournal of Cancer 25, $385-394$.

Rose, E. F. (1973). Fournal of the National Cancer Institute $51,7-16$.

Rose, E. F. (1981). Cancer Among Black Populations, pp. 67 [L. Mettlin and G. Murphy, editors]. New York: Alan R. Liss.

Sakula, A., Lutner, Z. A., Moore, T. \& Sharman, I. M. (1980). Lancet ii, 1029-1030.

Shehella, L. (1981). Lancet ii, I185-1 189.

Shine, I. \& Allison, P. (I 966$)$. Lancet $\mathrm{i}, 95 \mathrm{I}-953$.

Siassi, F. (1980). Federation Proceedings 39, 654 .

Siegler, E., Rettura, G. \& Levenson, S. M. (1981), Oncology News, 3 Sept, 63.

Simpson, K. C., Chichester, W., Skehelli, R. B., Lepper, M., Lui, S., Maliza, W. J., Raynor, W. J. \& Rossol, A. H. (1982). Annual Review of Nutrition I, $35^{1-374 . ~}$

Sporn, M. B. (1977). Nutrition Reviews 35, 65-69.

Sporn, M. B., Dunlop, N. B. \& Newton, D. L. (1976). Federation Proceedings 35, 1332-1 $33^{8}$.

Sporn, M. B. \& Newton, D. L. (1979). Federation Proceedings 38, 2528-2534.

Sporn, M. B. \& Newton, D. L. (198I). Retinoids and Chemo-prevention of Cancer pp. 71-100 [M. I. Zadek and M. Lipkin, editors]. New York: Plenum Press.

Torek, F. (1913). Surgery, Gynaecology and Obstetrics 16, 614-617.

Tuyns, A. F. \& Masse, G. (1975). Fournal of Epidemiology 4, 55-59.

Tuyns, A. F., Pequignot, G. \& Hensen, O. M. (1978). Cancer Bulletin 65, 58-64.

van Rensburg, S. J. (1981). Fournal of the National Cancer Institute 67, 243-251.

van Rensburg, S. J., Benade, A. S., Rose, E. F. \& du Plessis, J. P. (1983). Nutrition and Cancer 4, 206-2 16.

van Rensburg, S. J., Kruger, E. F. \& Louw, M. E. (1981). Nutrition Reports International 24, $1123-1126$.

Wald, N. J., Idle, M., Boreham, J. \& Bailey, S. (1980). Lancet i, 81 $13-815$.

Wangesteen, O. H. (1956). Cancer of the Oesophagus and Stomach, and ed. New York: American Cancer Society.

Warwick, C. P. \& Harington, J. S. (1973). Advances in Cancer Research 17, 81-229.

Waterhouse, J., Shanmugaratnam, K. \& Muir, C. (1982). Cancer Incidence in Five Continents, vol. IV. IARC Scientific Publication no. 14. Lyon:IARC.

Weisburger, J. H., Wynder, E. L. \& Horn, C. L. (1982). Cancer 50, 254 I-2549.

Werther, J. L. (1980). New York State Medical fournal 8, $1401-1408$.

Wychulis, A. R., Woolam, G. L. \& Anderson, H. A. (1971). Fournal of the American Medical Association $215,1638-164 \mathrm{I}$.

Wynder, E. L. \& Brom, I. J. (1961). Cancer 14, 389-413.

Wynder, E. L., Hultberg, S., Jacobson, F. \& Bross, I. J. (1957). Cancer 10, $470-487$. 